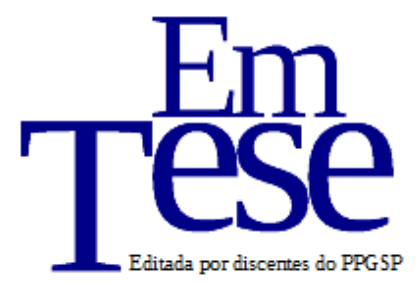

\title{
Estágio como ensaio, ensaio como forma: apropriações metódicas de como proceder metodicamente sem método
}

\author{
Antonio Alberto Brunetta ${ }^{1}$
}

O ensaio, ao contrário do método cartesiano, obriga a pensar a coisa, desde o primeiro passo, com a complexidade que lhe é própria (ADORNO, 2003, p. 33)

\section{A organização do estágio: reflexão coletiva e prolongada}

O projeto de estágio curricular do curso de Licenciatura em Ciências Sociais da Universidade Federal de Santa Catarina (UFSC) possui uma configuração bastante convencional, na qual ocorre uma articulação entre três disciplinas, quais sejam, Metodologia de Ensino de Ciências Sociais, de quatro (4) créditos; Estágio Supervisionado em Ciências Sociais I e Estágio Supervisionado em Ciências Sociais II, cada uma delas com quatorze (14) créditos, destes quatro (4) créditos de aula na universidade e dez (10) créditos relacionados às atividades no campo de estágio, as quais são oferecidas e devem ser cursadas em semestres consecutivos de modo a acompanhar o ano letivo da escola onde o estágio será realizado. Vale destacar que o trabalho de pesquisa realizado pelos alunos dessas disciplinas ocorre, salvo raras exceções, em duplas.

A disciplina de Metodologia de Ensino pretende ser o ponto de partida do contato dos licenciandos com a realidade escolar do ensino público, de modo que no plano de ensino da disciplina está objetivado - sob a forma de avaliação - a realização de pesquisa sobre uma escola pública de modo a contemplar, por exemplo, a análise do meio social e cultural no qual está inserida a escola; estudo do seu Projeto Político

\footnotetext{
${ }^{1}$ Doutor em Ciências Sociais, Professor do Departamento de Metodologia de Ensino (MEN) da Universidade Federal de Santa Catarina (UFSC) na área de metodologia de ensino de Ciências Sociais. Email para contato: aabrunetta@gmail.com
} 
Pedagógico; investigação sobre a disciplina de Sociologia na escola, o trabalho docente e a relação dos educandos com a disciplina.

Com esta experiência pretende-se que sejam construídas as primeiras interrogações que articulem às demandas do campo, os apontamentos teóricos e orientações curriculares oriundas, respectivamente, do estudo das diretrizes oficiais, de textos clássicos e contemporâneos sobre as temáticas relacionadas ao ensino de Sociologia; busca-se problematizar e capacitar os discentes em um panorama que abranja a escola e seu contexto, bem como os materiais didáticos e suas aplicações. Essa discussão se mantém articulada a natureza epistemológica das Ciências Sociais. O trabalho nessa disciplina é completado com a construção, por parte dos alunos, de um Programa de Ensino de Sociologia para uma das séries do Ensino Médio, o qual se fundamenta tanto na pesquisa realizada sobre o contexto escolar e o perfil dos alunos, mas também na pesquisa sobre os materiais didáticos possíveis e disponíveis, como é o caso dos livros didáticos aprovados em cada edital (2012 e 2015) do Plano Nacional do Livro Didático (PNLD).

A disciplina de Metodologia de Ensino é sistematicamente oferecida no segundo semestre de cada ano letivo, com vistas a que as disciplinas de Estágio Supervisionado I e Estágio Supervisionado II possam ser cursadas ao longo de um mesmo ano letivo, no qual o licenciando se integrará ao trabalho de um mesmo professor-supervisor e de uma mesma turma na disciplina de sociologia no Ensino Médio.

A disciplina Estágio Supervisionado I, que se inicia juntamente com a presença dos alunos no campo de estágio definitivo, se organiza pela articulação de três movimentos simultâneos, sendo eles: 1) a leitura sistemática de textos, que seguem uma linha que percorre a problemática do próprio estágio, em seguida problematiza concepções clássicas sobre aprendizagem - mais propriamente no campo das teorias da aprendizagem - para depois passar pelo debate acerca das questões relacionadas ao grande campo de questões que envolvem perspectivas e temáticas tais como: Filosofia, Política, Trabalho Docente, Ensino Médio, Juventude etc; 2) A realização de uma pesquisa junto ao campo específico de estágio, com o propósito de construir um panorama acerca dos estudantes, do docente e da equipe pedagógica, bem como das condições da escola e de seu entorno e; 3) a observação sistemática das aulas e demais atividades com as quais a turma de sociologia do Ensino Médio se envolva. De acordo 
com os movimentos da disciplina, é proposta a elaboração de um projeto de ensino, o qual abarca todas as informações recolhidas e reflexões suscitadas pela pesquisa no campo de estágio, além da construção do plano de ensino e dos planos de aulas, os quais compõem um Projeto de Ensino que servirá como planejamento para a intervenção mais direta, preconizada no Estágio Supervisionado II, no qual a regência se realizará.

A disciplina Estágio Supervisionado II, por sua vez, compreende a reelaboração do Projeto de Ensino, de tal modo que dele possa ser produzida também a reelaboração dos planos de aula para as regências, as quais ocupam o tempo de um bimestre ou trimestre, de acordo com o regime letivo da escola, em geral quatorze (14) semanas, com aulas duplas de cem (100) minutos, podendo variar conforme o funcionamento da escola. Ao longo desta disciplina, os encontros em sala de aula são ocupados com discussões coletivas, nas quais se pretende a orientação das atividades realizadas em campo, articulando reflexivamente os elementos intelectualmente acumulados desde a primeira das três disciplinas.

Ao final da disciplina Estágio Supervisionado II os alunos confeccionam um relatório final que é composto por todos os materiais produzidos nas disciplinas anteriores, acrescentados de uma reflexão específica sobre as regências, em seus aspectos objetivos e subjetivos. As atividades realizadas nas três disciplinas são finalizadas em um simpósio com a presença dos alunos das turmas do matutino e noturno, momento marcado pela socialização das experiências.

Uma "reflexão coletiva e prolongada", esta seria uma definição sintética, porém pertinente, da maneira como, na experiência de Estágio Supervisionado em Ciências Sociais na UFSC, são rearticuladas as perspectivas dos docentes e licenciandos que nela interagem e a concepção de Pimenta e Lima (2004) que nos orienta de modo basal, e segundo as quais a pesquisa deve se colocar como eixo articulador do estágio.

Essa descrição, bastante reduzida da proposta de estágio que aqui se problematiza, tem como propósito formativo estabelecer apenas as linhas gerais de um desenho bastante complexo que dá origem ao que se transforma em substrato de memória para as demais experiências docentes dos licenciandos; para este texto cumpre a função de situar o leitor diante da maneira como são definidas as rotinas e as dinâmicas do Estágio Supervisionado do Curso de Licenciatura em Ciências Sociais na UFSC. Destarte, torna-se possível apresentar de modo objetivo algo que na prática 
ocorre de maneira bastante dinâmica, sobretudo quando se considera como material empírico específico desta análise, as mais de cinquenta (50) horas de observação das regências de quatro (04) duplas de estagiários, distribuídas em sete (07) semanas de convívio em meio às rotinas escolares. Entretanto, a proposta de estágio que se busca promover, em termos gerais, começou a ser gestado nos anos 1990, e por sua natureza, não se espera, nem se pretende, que a concepção "envelheça", pois a concepção de estágio como pesquisa se ocupa justamente de ser dinâmica, tal como os processos educacionais com os quais cotidianamente nos defrontamos

\section{Estágio como ensaio}

Muito embora se estabeleça na pesquisa o ponto de superação da tradicional dicotomia entre teoria e prática (PIMENTA; LIMA, 2004) o tratamento a posteriori do que se observou - e foi considerado junto aos estagiários logo em seguida às regências traz como pressuposto o entendimento segundo o qual o momento do estágio é também de ensaio. Isto implica considerar ao menos dois conteúdos semânticos da palavra ensaio: primeiro, e mais imediato, aquele momento em que se prepara algo de modo experimental, preliminar, e não de fato; segundo, aquele estilo de escrita cuja preocupação com a forma guarda a mesma relevância que a preocupação com o conteúdo.

Sobre o primeiro dos significados atribuídos a palavra ensaio é pertinente considerar que, se de um lado, apesar dessa orientação não permitir, de fato, diminuir de modo efetivo a ansiedade que caracteriza essa "inauguração" da relação do licenciando com o trabalho da docência, por outro lado, tomá-la como horizonte permite ao professor-orientador e ao professor-supervisor elaborarem de modo equilibrado as suas próprias ansiedades diante das "dificuldades" dos licenciandos nas múltiplas atribuições que lhe são exigidas, desde a verificação da frequência, até o trato com os conceitos; desde a burocracia escolar, até a construção de explanações de uma aula expositiva; sem deixar de considerar a aplicação da metodologia que se elegeu para a aula, até o trato com as questões disciplinares; e, especialmente relevante é (conforme relato dos próprios estagiários) o fato de se estar na presença do orientador e do supervisor. 
De modo complementar à primeira noção de ensaio, importa dizer que a comparação com o estilo literário carrega a preocupação, deliberadamente permissiva, mas não menos atenta - e tão rigorosa quanto possível, nas orientações posteriores às regências - em relação à criação de condições que sejam propícias à construção de um sentido próprio à prática docente por parte do estagiário, de tal modo que o planejamento da aula a ser ministrada na regência seja dotado de significação para o estagiário, sendo então possível o compartilhamento dessa significação com os alunos.

Assim, tal como propõe Adorno para o ensaio literário, quando se aplica a construção do texto filosófico ou sociológico, "Escreve [leciona] ensaísticamente quem compõe [planeja e ministra a aula/regência] experimentando" (ADORNO, 2003, p. 35). Portanto, com a supramencionada permissividade deliberada "Não se pretende que a arte [aula/regência] seja uma reserva de irracionalidade" (ADORNO, 2003, p. 29), mas que seja sim a [aula/regência] que evoque "aquela liberdade de espírito que, após o fracasso de um iluminismo cada vez mais morno [...] até hoje não conseguiu se desenvolver adequadamente, nem mesmo sob as condições de uma liberdade formal [...]" (ADORNO, 2003, p. 16).

A possibilidade de encarar as contradições próprias ao trabalho docente contradições estas presentes até mesmo no trabalho de professores de longa experiência - apresenta-se como um passo coeso no escopo das noções mais primárias do materialismo, capacitadas a produzir uma experiência de trabalho que, mesmo não sendo imune à alienação, esteja ao menos preparada para desmistificá-la, pois parte-se do entendimento segundo o qual:

\begin{abstract}
O ensaio [estágio] reflete o que é amado e odiado, em vez de conceber o espírito como uma criação a partir do nada, segundo um modelo de uma irrestrita moral do trabalho. Felicidade e jogo lhe são essenciais. Ele [o estágio/a aula/regência] não começa de Adão e Eva, mas com aquilo sobre o que deseja falar, diz o que a respeito lhe [ao estagiário] ocorre e termina onde sente ter chegado ao fim, não onde nada mais resta a dizer: ocupa, desse modo, um lugar entre os despropósitos (ADORNO, 2003, p. 16-17).
\end{abstract}

As observações dos estágios proporcionam constatar que o lugar ocupado pelo estagiário é algo como um lugar indefinido, pois mesmo que concebido como ensaio (preparação para algo de fato), o estágio não é, propriamente, uma aula para uma turma 
em uma escola, portanto, uma atividade na qual o estagiário tenha as vinculações efetivas. Vivendo um simulacro, mas estando sob observação de agentes reais (supervisor, orientador e estudantes), o estagiário pode ser portador da insígnia do intérprete, do ator, daquele a quem, inelutavelmente, a tarefa de construir-se como um outro se apresenta como desafio inglório, haja vista que "Quem interpreta [estagiário], em vez de simplesmente registrar e classificar, é estigmatizado como alguém que desorienta a inteligência para um devaneio impotente e implica onde não há nada para explicar" (ADORNO, 2003, p. 17).

Nessa tarefa multidimensionalmente constituída pelos olhares de supervisor, orientador e alunos, ao estagiário pode [e talvez deva] ser oferecida, pela perspectiva do ensaio - ainda que forjada ao longo dos semestres que antecedem a regência propriamente - a possibilidade da liberdade em relação às exigências dessa, também múltipla, "clientela" de avaliadores (supervisor, orientador, alunos), pois "Livre da disciplina da servidão acadêmica, a própria liberdade espiritual perde a liberdade, acatando a necessidade pré-formada da clientela" (ADORNO, 2003, p. 20).

Para as experiências de estágio, que se configuram com uma complexidade ainda maior que a de uma aula regular - tendo em vista o que está em jogo -, e conforme as observações, é possível inferir que há pertinência no ousar, de modo a garantir que as múltiplas relações constituídas possam ocupar um patamar equivalente ao dos conteúdos/problemas/conceitos/etc. que se pretenda apresentar. Leva-se em conta que "O ensaio [estágio] não segue as regras do jogo da ciência e da teoria organizadas, segundo as quais, com diz a formulação de Spinoza, a ordem das coisas seria o mesmo que a ordem das ideias" (ADORNO, 2003, p. 25).

Neste ponto dessa reflexão é de grande valia apresentar uma situação de estágio como exemplo daquilo que aqui se entende como sendo a "ordem das coisas" (e dos acontecimentos) segundo nos lembrou Adorno (2003, p. 25) ao referir-se a Baruch Spinoza.

Em uma das regências observadas, as estagiárias trabalhavam, no campo da Ciência Política, os autores clássicos da Filosofia Política; assim, apresentavam os teóricos contratualistas em suas diferentes proposições acerca da organização social. Destarte, as perguntas, os debates, as discussões, em síntese, as inquietações que a aula, inexoravelmente, provocava eram compostos por questões ligadas à "propriedade 
privada e coletiva", à "liberdade", à "soberania", ao "autoritarismo", à "subsunção e submissão do indivíduo ao poder estabelecido", mas, sobretudo à discussão acerca da "participação e da representação políticas". Talvez isso tenha ocorrido por tratar-se de algo palpável e mais próximo aos alunos, os quais teriam seu título de eleitor em um futuro alcançável.

Em meio aos questionamentos e as explicações acerca das formas de participação e representação políticas, a aula foi interrompida por um grupo de alunos composto pelo presidente do Grêmio da escola e por outros dois estudantes pertencentes a atual gestão da União Brasileira dos Estudantes Secundaristas (UBES), os quais pediram permissão às estagiárias para trazerem informações acerca do próximo congresso da instituição, no qual a pauta principal seria a eleição de uma nova diretoria. Além de trazer a informação aos alunos, a pequena comitiva pretendia também consultá-los acerca de uma proposta segundo a qual o atual presidente do Grêmio da escola fosse aprovado como delegado daquela escola no congresso, ao invés de se eleger um representante específico para tal tarefa.

Considera-se que não sejam necessários mais parágrafos para caracterizar a profunda relação estabelecida entre o ocorrido nessa regência acima relatada, e a temática que orientava aula. Todavia, é preciso destacar, que apesar do absoluto domínio do conteúdo por parte das estagiárias, nada acerca do ocorrido foi dito pelas estagiárias aos alunos ou com eles problematizado. Ao orientador, que observava do fundo da sala a cena, sobressaltaram segundos de silêncio que, a despeito daquela ser uma turma de alunos bastante agitados, eram representativos da expectativa sagaz dos discentes, de que algo de pertinente lhes escapava e que poderia ter sido exposto pelas estagiárias, de modo a lhes garantir que algo daquela experiência, tão transitória quanto sincronizada, fosse amalgamado didática e pedagogicamente. Entretanto, a aula retomou seu fluxo, que apesar de dialógico, ignorou por completo o substantivo transitório que lhe atingiu.

É evidente que não se ensaia para o improviso, nem é isso que se deseja ao formar professores, no entanto, é preciso considerar que o ensaio pode nos levar para além do domínio do script, à verdade contida nos conceitos. Igualmente, não se pretende que os estágios se estabeleça na dependência de episódios, mas é inegável que 
se possa dar conta deles, bem como se apropriar da materialidade que eles nos oferecem de modo tão direto em relação ao que se apresenta e discute em sala de aula.

\begin{abstract}
O ensaio [estágio/regência] porém, não quer procurar o eterno no transitório, nem destilá-lo a partir desse, mas sim eternizar o transitório. A sua fraqueza testemunha a própria não-identidade, que ele deve expressar; testemunha o excesso de intenção sobre a coisa e, com isso, aquela utopia bloqueada pela divisão do mundo entre o eterno e o transitório. No ensaio [estágio/aula/regência] enfático, o pensamento se desembaraça da idéia tradicional de verdade (ADORNO, 2003, p. 27).
\end{abstract}

Adorno é ainda mais contundente:

O ensaio [estágio/aula/regência] [...] incorpora o impulso anti-sistemático em seu próprio modo de proceder, introduzindo sem cerimônias e "imediatamente" os conceitos, tal como eles se apresentam (ADORNO, 2003, p. 28).

A noção de estágio como ensaio, portanto, pretende oferecer aos estagiários um protagonismo - e espera que o estagiário o reivindique - de modo que a experiência, antes temerosa e plena em ansiedades, seja apropriada como experiência intelectual propriamente, o que implica e significa dotar-se de liberdade diante de um cenário tendencialmente repressor porque múltiplo e permanentemente avaliativo.

Se organizado a partir de tal premissa, o estágio poderá ser capaz de facultar ao estagiário, também e especificamente no momento de sua regência, a condição reflexiva, esta tão cara a todas as teorias educacionais que se pretenderam progressistas, proporcionando condições nas quais "o pensador [estagiário], na verdade, nem sequer pensa, mas sim faz de si mesmo o palco da experiência intelectual, sem desemaranhá-la [...] O ensaio [estágio/aula/regência] procede, por assim dizer, metodicamente sem método" (ADORNO, 2003, p.30).

Há também que se considerar na experiência de estágio um dado substantivo da episteme das Ciências Sociais, qual seja, o da ausência de consenso, e consequentemente, das exigências em se trabalhar diferentes abordagens teóricas e se deparar com um histórico reduzido de envolvimento em uma ou em outra perspectiva de análise. Nesse ponto, seria possível enumerar uma série de exemplos que remeteriam uma diversidade expressiva de razões pelas quais os estagiários não são portadores de tão diversos requisitos. 
Mas quanto às razões, essas vão desde a organização do currículo da Sociologia no Ensino Médio, o qual é, em grande medida, a expressão das escolhas do professor supervisor. Esta organização passa pelas limitações originadas nas tendências que predominaram na formação do estagiário ao longo dos quatro anos de formação no curso de graduação - tanto em relação às disciplinas, como também nos projetos de iniciação científica, entre outros -; passam também pelas predileções e escolhas dos próprios licenciandos; e incluem (sem findar o elenco) na diversidade exponencialmente crescente dado o cruzamento das áreas das Ciências Sociais (Antropologia, Ciência Política e Sociologia) incluindo os numerosos autores e as infinitas temáticas... assim, se está diante de um universo enorme de referências, em que até mesmo o mais erudito dos intelectuais, se preocupado com a isonomia, teria dificuldades em fazer suas escolhas.

Em meio a essa dificuldade estrutural, a noção de estágio se apresenta novamente como alento (nunca como solução), de maneira a permitir encontrar no contexto das incertezas decorrentes das diversidades um escopo de interlocução com as preferências. Acrescente-se nessa busca o compromisso do orientador em conhecer e reconhecer minimamente as diferentes áreas, autores e temáticas, para poder realizar seu trabalho de modo a contribuir nas combinações propostas pelos estagiários de modo a compor uma unidade dotada de sentido e realizável em quatorze (14) semanas.

E, por mais uma vez, adota-se como base desta reflexão os acontecimentos ocorridos no período analisado, registrando que na porta de uma sala de aula para uma das regências, enquanto aguardávamos a saída do professor que havia acabado de ministrar sua aula da (disciplina de Química), o orientador fora interpelado e recebeu do professor de Química o provocativo questionamento: "Vai ser aula de Sociologia mesmo ou doutrinação bolivariana?". De imediato, e atropelado pela prepotência com que as palavras foram pronunciadas, apenas foi possível ao orientador perguntar o nome do professor de Química e, em seguida, responder-lhe que se tratava sim, de "aula de Sociologia".

Ao longo da semana o orientador foi atormentado pelo orgulho e pela necessidade de responder ao professor de Química, a quem na semana seguinte, afirmado simplesmente que: não fora elegante da parte dele abordar o orientador daquela maneira; de modo também simples e breve foi registrado que os ideais da 
revolução bolivariana possuíam pertinência histórica e sociológica, e poderiam sim, figurar como conteúdos das aulas quando julgados pertinentes, pois faziam parte da diversidade de fatos sociais, os quais - de acordo com a compreensão do professor orientador de estágio de Sociologia, da supervisora, dos estagiários e dos alunos receberiam a mesma relevância que outros momentos e ideários políticos nos quais a tendência ideológica fosse distinta. Ainda justificado que essa era a perspectiva adotada por todos os envolvidos com o estágio da área de Sociologia, tendo em vista que não o trabalho de ensinar Sociologia não se pautava por preconceitos, mas se inclinava fortemente a desconstruí-los, e assim o orientador esperava fazê-lo também em relação aos possíveis preconceitos que o professor de Química estivesse manifestando. Tudo isso foi dito sem interrupções. Em resposta, o professor de Química se justificou, por meio da referência à unidade ideológica de professores de outra área de conhecimento, a qual ele considerava problemática porque restritiva para a formação dos alunos; mas, por fim, se desculpou.

No contexto de disputas ideológicas candentes, que até mesmo transcendem o espaço acadêmico e disciplinar das Ciências Sociais, urge mais uma aproximação com Adorno, pois:

\footnotetext{
O ensaio [estágio/aula/regência] não apenas negligencia a certeza indubitável, como também renuncia ao ideal dessa certeza. Torna-se verdadeiro pela marcha de seu pensamento, que o leva para além de si mesmo, e não pela obsessão em buscar seus fundamentos como se fossem tesouros enterrados (ADORNO, 2003, p.30).
}

São circunstâncias como as acima descritas que justificam a abordagem que aqui se esboça, a qual reitera o rigor da orientação metódica por parte do orientador, somado ao compartilhamento dessas experiências com o supervisor e os estagiários, de modo a tornar as demandas ainda mais explícitas quanto mais abrangentes e diversificadas estas se mostrarem.

\section{Estágio como forma}

Sendo assim, a permissividade deliberada que ancora essa abordagem não é concebida e conduzida de modo inadvertido, mas justamente pretende ser o substrato da atenção necessária ao docente em formação, aquele para quem, independentemente das 
inovações metodológicas, naquilo que ela possa promover em termos de descentralização do papel do docente em sala de aula, não o furtam na responsabilidade inerente de sua condição institucional, nem mesmo lhe eximem da condição de alvo frente às ideias veiculadas por seus alunos, sejam estas promotoras de sucessos ou insucessos no desempenho discente.

O professor não possui, por certo, a responsabilidade exclusiva pelo futuro de seus alunos, menos ainda o estagiário, mas persistirá sobre ele a condição daquele que ao proclamar seus juízos permanecerá presa fácil da crítica leviana e arbitrária daqueles que concebem a escola como realidade isenta de influências externas e que, consequente e ingenuamente, deduzem que surgirá da isenção no processo educativo a capacidade harmonizadora para a sociedade.

Por isso, e por fim, “O ensaio [estágio/aula/regência] não utiliza equívocos por negligência, ou por desconhecer o veto cientificista que recai sobre eles, mas para recuperar aquilo que a crítica do equívoco, a mera distinção de significados, raramente alcançou [...]" (ADORNO, 2003, p. 43). O contraditório persiste, sendo a atualidade do ensaio [estágio/aula/regência] a do anacrônico, e a forma de tratá-lo, enquanto formadores de professores, se coloca em oposição à concepção cartesiana, como nos sugere a epígrafe deste texto.

\section{Referências}

ADORNO, T. W. O Ensaio como forma. In: . Notas de Literatura. $34^{\mathrm{a}}$ ed. São Paulo: Duas Cidades, 2003.

PIMENTA, S. e LIMA, M. do S. Estágio e docência. Coleção Docência em formação. São Paulo: Cortez, 2004. 


\title{
Estágio como ensaio, ensaio como forma: apropriações metódicas de como proceder metodicamente sem método
}

Resumo: Este ensaio problematiza as experiências de quatro (04) duplas de estagiários da disciplina de Estágio Supervisionado em Ciências Sociais II, durante o segundo semestre do ano de 2013 no Ensino Médio, do Colégio de Aplicação, da Universidade Federal de Santa Catarina. O tratamento teórico adotado orienta-se pelo texto Ensaio como forma, da obra Notas de Literatura I, de Theodor W. Adorno, o qual permite a construção de uma narrativa sobre essas experiências, as quais são entendidas por sua natureza ensaística sem dispensar o rigor acadêmico e a reflexão estética. Foram cinquenta e seis (56) horas de observação, em sete (07) semanas. Os resultados apontam para a necessidade de fortalecer a relação entre teoria e prática a partir da valorização da dimensão e do caráter experimental das aulas de regência e da assunção de sua dimensão subjetiva.

Palavras-chave: Estágio Curricular; Ensaio; Theodor Adorno; Ensino de Sociologia

\section{Training apprenticeship as rehearsal, essay as form:}

\section{methodical appropriations of what to do methodologically without method}

\begin{abstract}
This essay discuss the experiences of four (4) trainees pairs from the discipline of Supervised Internship in Social Sciences II, during the second half of 2013 in a high school of the Federal University of Santa Catarina. The theoretical treatment used is guided by the text called "Essay as a form" in Literature Notes I of Theodor W. Adorno, which allows the construction of a narrative about these experiences, which are understood by his essayistic nature without giving up the academic accuracy and aesthetic reflection. There were fifty six (56) hours of observation, in seven (07) weeks. The results point to the need to strengthen the relationship between theory and practice from the appreciation of the dimension and the experimental nature of conducting classes and the assumption of its subjective dimension
\end{abstract}

Keywords: Curricular Training; Essay; Theodor Adorno; Sociology of Education 
Recebido em: 12 de maio de 2015.

Aceito para publicação em: 15 de agosto de 2015. 